\title{
A COMUNICAÇÃO ENTRE OS PROFISSIONAIS DE PEDIATRIA E A CRIANÇA HOSPITALIZADA*
}

\section{THE COMMUNICATION BETWEEN PEDIATRICS PROFESSIONALS AND THE HOSPITALIZED CHILD}

\author{
Cláudia Batagin Armelin ${ }^{* *}$ \\ Rodrigo Ambros Wallau*** \\ Cynthia Andersen Sarti ${ }^{\ddagger}$ \\ Sonia Regina Pereira ${ }^{\ddagger \ddagger}$
}

\begin{abstract}
Armelin CB, Wallau RA, Sarti CA, Pereira SR. A comunicação entre os profissionais de pediatria e a criança hospitalizada. Rev Bras Cresc Desenv Hum 2005; 15(2):45-54.

Resumo: O estudo trata das dificuldades de comunicação entre profissionais de saúde e pacientes pediátricos em situação de hospitalização. Considerando que uma comunicação efetiva implica o reconhecimento mútuo, buscamos o ponto de vista tanto dos pacientes e seus familiares quanto dos profissionais, para entender como se dá a comunicação entre um e outro e como se estabelecem as relações entre ambos. Dado o problema da pesquisa, a metodologia é qualitativa e o método, o estudo de caso. $\mathrm{O}$ trabalho de campo foi desenvolvido em um hospital público universitário na cidade de São Paulo. Foram selecionadas para estudo duas crianças em idade escolar e que permanecessem internadas por um período maior do que uma semana. Foi feito um acompanhamento sistemático de cada uma das crianças, por meio da técnica de observação, e foram entrevistados seus acompanhantes e os profissionais envolvidos em seu cuidado e tratamento, englobando parte significativa do universo de comunicação interpessoal da criança hospitalizada. Verificamos que a comunicação se estabelece preferencialmente entre o profissional e o acompanhante, em função da criança, mas nem sempre com a participação desta, deixando a criança em um plano secundário no campo das relações.
\end{abstract}

Palavras-chave: Comunicação. Criança hospitalizada. Relação profissional-paciente. Cuidado infantil. Pediatria.

\section{INTRODUÇ̃̃O}

Este estudo teve como problema de investigação as dificuldades de comunicação observadas entre os profissionais da saúde e o paciente pediátrico e seu acompanhante no âmbito da hospitalização.

A repercussão emocional deste fato para a criança tem sido, de modo geral, pouco considerada no meio pediátrico. No entanto, trabalhos de profissionais de diversas áreas, publicados desde a década de 1930, revelam a crescente preocupação com a questão da saúde mental da criança, durante e após a hospitalização. Bordin e Corrêa ${ }^{1}$ demonstraram que a doença, como qualquer situação de crise, altera a

\footnotetext{
Artigo baseado na pesquisa de Iniciação Científica, "A comunicação entre os profissionais, o paciente e o acompanhan te e suas repercussões na assistência à criança hospitalizada", Deptos de Medicina Preventiva e de Enfermagem da (UNIFESP), apoio Fundação de Amparo à Pesquisa do Estado de São Paulo.

** Aluna do Curso de Medicina da UNIFESP, bolsista PIBIC-FAPESP. cbarmelin@ hotmail.com.

*** Aluno do Curso de Medicina da UNIFESP, bolsista PIBIC-FAPESP. rwallau@ hotmail.com.

$\ddagger \quad$ Professora. Livre Docente do Departamento de Medicina Preventiva UNIFESP e orientadora. csarti@uol.com.br.

执 Professora Adjunta do Departamento de Enfermagem da UNIFESP e co-orientadora. sore@ @enf.epm.br
} 
vida da criança e de sua família, gerando ansiedade. A necessidade de hospitalização é um fator agravante, que pode constituir uma experiência bastante difícil para o paciente pediátrico e sua família. Essa vivência pode levar tanto a um amadurecimento e, a um maior desenvolvimento psíquico, como resultar em prejuízo para o desenvolvimento físico e mental da criança.

O sucesso no enfrentamento da doença depende de muitos fatores, entre os quais estão as concepções da criança, da família e da própria equipe de saúde relativas à doença e às chances de recuperação ${ }^{2}$. Considerando a afirmação de Tosta ${ }^{3}$, podemos dizer que o modo como cada pessoa enfrenta a doença depende dos recursos de que dispõe para obter conhecimento sobre sua doença e sua experiência de hospitalização e, assim, enfrentar da melhor maneira, que lhe for possível, os conflitos gerados.

Para tanto, Sadala ${ }^{4}$ afirma que a elaboração da forma de viver essas situações, pela criança, pode se dar pela oportunidade de expressar os seus sentimentos em relação a experiências vividas como traumáticas, dando vazão à ansiedade, à raiva e à hostilidade, o que requer recursos disponíveis para que a criança se manifeste. Essa ajuda poderá ser proporcionada por um relacionamento que permita alguma estabilidade e algum vínculo, dadas as características particulares de dependência que a criança apresenta com relação aos profissionais que a rodeiam durante a hospitalização.

Na relação entre o profissional e o paciente, Viegas ${ }^{5}$ enfatiza a necessidade de credibilidade e sensibilidade para o estabelecimento de uma comunicação terapêutica. Esta exige, segundo Hofling et al. ${ }^{6}$, alguns elementos básicos por parte do profissional: empatia e envolvimento com o paciente, além do sentimento de confiança entre ambas as partes.

A necessidade desta comunicação é enfatizada, ainda, no trabalho de Bodin e Corrêa ${ }^{1}$, que estabelece uma associação entre a ansiedade da criança hospitalizada e a distância na relação entre o médico e o paciente, o que impede a percepção clara por parte da criança da realidade por ela vivida.

Uma comunicação efetiva implica o reconhecimento mútuo. Diz respeito à concepção de cada um sobre si e sobre o outro. Envolve, portanto, uma relação entre dois sujeitos. Assim, considerando a importância da comunicação nas relações humanas e a particularidade da situação de hospitalização, a indagação desse trabalho refere-se às formas de comunicação entre os profissionais, o/a paciente e seu acompanhante, no âmbito da enfermaria pediátrica, uma vez que, tal como afirma a literatura ${ }^{1,4,8,9}$, as relações estabelecidas são decisivas para o tratamento e a recuperação da doença e para uma qualidade de vida suficientemente boa - parafraseando Winnicott, ao se referir à mãe "suficientemente boa", distante de qualquer idealização? .

Dado o problema do estudo, nosso objetivo foi o de observar e analisar como acontece a comunicação entre a criança, o acompanhante e o profissional da saúde em uma enfermaria pediátrica; e, ainda, avaliar se a indagação dos pesquisadores era considerada um problema para os protagonistas da situação estudada.

\section{MÈTODOS}

\section{A Pesquisa}

O estudo foi realizado em enfermarias pediátricas de um hospital público universitário da cidade de São Paulo. O método aplicado foi o do "estudo de caso", tal como formulado pelas ciências sociais, que toma como unidade de análise não necessariamente um caso individual, como acontece na pesquisa médica e psicológica, mas uma situação socialmente delimitada, ou seja, uma organização ou comunida$\mathrm{de}^{10}$. Assim, definimos a enfermaria pediátrica como o caso a ser estudado, em sua organização e nas relações que se desenvolvem neste 
âmbito hospitalar.

Para a coleta dos dados que permitissem responder nossos questionamentos, dividimos o trabalho de campo em duas fases. Na primeira, fizemos a observação da dinâmica na enfermaria, com o intuito de conhecer o funcionamento da mesma, pois entendemos que só a partir do momento que conhecêssemos como as pessoas se relacionam e o lugar de cada uma delas na organização do trabalho, é que poderíamos fazer uma análise mais específica da comunicação existente entre elas. A etapa de observação foi realizada por ambos pesquisadores de iniciação científica, no período de janeiro a março de 2002, nos turnos da manhã e da tarde. † Tais observações realizaram-se em todo o espaço que constitui o serviço de atendimento das enfermarias de clínicas pediátricas: nos quartos, na sala de reunião dos médicos, nos corredores e no anfiteatro.

Quando obtivemos uma visão geral do funcionamento do serviço e dos aspectos relevantes para a comunicação, na enfermaria, passamos à segunda fase, com o objetivo de escutar os protagonistas das cenas observadas, a fim de realizar uma análise mais específica e aprofundada da comunicação da criança e seu acompanhante com os profissionais que lhes prestavam assistência. Para tanto, foi feito um acompanhamento sistemático de duas crianças - uma por cada pesquisador -, incluindo entrevistas com seus acompanhantes e com os profissionais que as atendiam.

Os critérios para seleção das crianças foram: idade maior que sete anos, que corresponde à idade escolar, pois, segundo Piaget ${ }^{15}$, em torno desta idade a criança deixa para trás o pensamento concreto e passa a ter a capacidade de representar a realidade e a refletir abstratamente sobre ela ${ }^{16,17}$, facilitando a comunicação requerida pelas técnicas utilizadas; e pe- ríodo de internação na enfermaria não inferior a uma semana, a partir do primeiro contato do pesquisador com a criança em questão, o que permitiria uma convivência, condição para a interação necessária à realização das entrevistas. Para tal, foi perguntado aos responsáveis pelas enfermarias quais seriam as crianças que permaneceriam o tempo necessário para coleta dos dados e quais seriam as crianças que porventura aceitariam participar do estudo.

Após selecionar as crianças hospitalizadas e obter o consentimento dos responsáveis por elas, mediante a assinatura do "Termo de Consentimento Livre e Esclarecido" - conforme exigência do Ministério da Saúde, em sua Resolução ${ }^{\circ} 196$ sobre pesquisas envolvendo seres humanos -, passamos aos procedimentos metodológicos previstos. Foram entrevistados os principais acompanhantes da criança durante a internação e todos os profissionais das enfermarias que entraram em contato direto com a criança durante o período de acompanhamento da mesma. As entrevistas eram abertas, com roteiro prévio - distinto para cada informante: acompanhante ou profissional -, foram gravadas e transcritas na íntegra.

Para análise dos dados coletados, foi feita a "triangulação" das informações das distintas fontes, tanto dos registros dos prontuários, como da observação e das entrevistas ${ }^{18}$, seguindo o caminho proposto por Becker ${ }^{10}$ para analisar o material de campo: começar por fazer a seleção e a definição dos problemas, verificar a freqüência e distribuição dos fenômenos e incorporar as descobertas individuais. No entanto, essa sequiência é apenas um recurso para organização dos dados, porque, na prática de pesquisa baseada em observação, essas fases ocorrem simultaneamente, não sendo possível separá-las de forma estanque, porque a análise começa a ser feita enquanto o pesquisa-

Para essa etapa da pesquisa, foi feita a leitura orientada de textos que subsidiassem o trabalho de observação, de acordo com os procedimentos metodológicos das ciências sociais ${ }^{10-14}$. 
dor está coletando os dados. Assim, utilizamos articuladamente todo o material coletado, integrando os dados na apresentação dos resultados, que correspondem aos principais problemas levantados pelo trabalho de campo.

As crianças selecionadas, Denis e Reginaldo (nomes fictícios, para garantir o anonimato dos entrevistados), tinham doze e catorze anos respectivamente. Ambas crianças dispuseram-se a participar da pesquisa e a escolha resultou favorável uma vez que nessa faixa etária percebe-se uma flexibilização no modo de pensar, característica deste momento de vida, que fornece uma riqueza imensa ao conteúdo pensado, que, daí em diante ocorrerá no plano das idéias, desvinculando-as das situações vividas, podendo refletir sobre elas e emitir opiniões ${ }^{17}$ Tanto Denis, como Reginaldo eram estudantes em escolas públicas. Denis estava internado pela primeira vez, devido a um quadro infeccioso agudo (osteomielite), enquanto Reginaldo apresentava uma experiência de internações recorrentes por complicações de anemia falciforme. A patologia não foi um fator determinante na escolha dos entrevistados, mas sim a diversidade na experiência de hospitalização, que permitiu a comparação da comunicação nas duas situações. O acompanhante principal nos dois casos foi a mãe, substituída em alguns momentos pela tia materna (caso do Denis) e pelo irmão (caso do Reginaldo). ${ }^{\dagger \dagger}$ Esclarecemos que no hospital onde foi realizado o estudo, adota-se a regra de não apenas permitir, mas também solicitar a presença de um acompanhante durante a internação da criança.

Para a busca de informações com as crianças, o trabalho iniciou-se pelo desenvolvimen- to da relação de empatia e confiança com as mesmas, valendo-se, cada pesquisador, de métodos próprios e pertinentes para a abordagem que consistia em sucessivas visitas a criança. Após o estabelecimento do vínculo de confiança entre o pesquisador e a criança, pudemos levantar as informações desejadas, realizando entrevistas abertas, gravadas em fita cassete e transcritas (além do uso da técnica do desenho, não incorporada no presente estudo).

Foram entrevistados três médicos, três enfermeiras, cinco auxiliares de enfermagem, uma psicopedagoga, uma recreacionista, as duas crianças e quatro acompanhantes (as mães, a tia materna de Denis e o irmão de Reginaldo) duas crianças selecionadas, totalizando 19 entrevistas.

\section{DISCUSSÃO DOS RESULTADOS}

A concepção que norteia o trabalho na Enfermaria de Pediatria estudada foi retratada por um dos profissionais de saúde que ali trabalham: nós aqui da pediatria trabalhamos em uma equipe multiprofissional, todos os profissionais trabalhando para o bem do paciente (enfermeira). Observamos que existe, de fato, uma interação entre os profissionais e uma busca de um atendimento de qualidade para as crianças internadas: eu acho que, para mim, a equipe tem que ter interprofissionais, para a gente tentar ver realmente os aspectos do paciente, do ser humano que esta aí sob todos os ângulos ....eu acredito na equipe que tenha este olhar (...) eu acho que a escola busca essa humanização, que é bem

\footnotetext{
A mãe de Reginaldo era solteira, empregada doméstica (diarista), cursava o ensino médio, tinha 35 anos à época e mais quatro filhos; a filha mais velha, de 19 anos, estava grávida no momento da pesquisa. Seu pai era uma figura ausente, tanto da situação de hospitalização como na fala dos entrevistados. Denis era filho de pais separados, morava com a mãe, uma irmã mais nova e um irmão adotivo; sua mãe tinha 44 anos, estava desempregada à época, sobrevivendo com ajuda da família, segundo seu relato. Era copeira, com ensino básico completo. O pai de Denis trabalhava como seguran ça à noite, tinha uma outra filha de um segundo casamento; durante a pesquisa, foi "visitar" o filho no hospital uma vez, não configurando uma situação de acompanhante em momento algum.
} 
por aí, você ser visto em todas as suas necessidades e as suas facetas também (psicopedagoga).

Essa busca por qualidade no atendimento não se refere apenas à criança, mas à família desta também. Há, por parte dos profissionais, uma forte referência ao mundo familiar da criança, que os leva à identificação da figura da criança com a do acompanhante, como se fossem um, sendo que esta unidade, no caso, corresponde à idéia de família. Pensa-se que o bem estar de um depende do bem estar do outro, e, assim, há uma preocupação com a garantia da qualidade de vida da família, não apenas da criança hospitalizada, como é expresso pela fala de uma enfermeira: $A$ gente em pediatria não pode dissociar a criança dos familiares, não pode porque é um binômio a gente fala, não é só a criança, tem que ver a criança e a família. (...) a gente gostaria que fosse uma coisa tranqüila, que a criança se visse internada, mas ainda percebesse a presença dos irmãos, dos priminhos, a gente tenta liberar isso.

Os profissionais da enfermaria relatam ter um bom relacionamento com os acompanhantes das crianças internadas. Eles afirmam que a presença do acompanhante é fundamental para a criança, para o cuidado e a garantia da qualidade de vida desta, como argumentado na literatura ${ }^{19,20}$. Segundo um médico, tinha crianças que não tinham acompanhante num setor que eu fiquei. Ah, elas são super carentes. Não têm com quem conversar direito, ficava isolada. Depende da idade. Depende da idade da criança. As menorzinhas eu acho que sentem muita falta.

Dentro da concepção do paciente pediátrico como parte da unidade familiar, o acompanhante também é fundamental para que o profissional possa se aproximar da criança. Este procura primeiro conquistar a confiança do acompanhante, o que, acredita, permite uma abordagem mais segura e garantida da criança. Percebemos, então, que os profissionais não abordam, diretamente, a criança, o que reitera a concepção da criança, por parte do profissional, como um ser que não se separa da família na qual se insere. A criança está sempre associada à figura da mãe/acompanhante. Como expressou uma psicopedagoga: para mim, para chegar no paciente eu tenho que passar pelo acompanhante, então assim, eu procuro primeiro fazer uma grande relação com os acompanhantes, também porque através da...porque a criança confia muito no acompanhante que ela tem, então se o acompanhante vai com a cara do profissional a criança também vai.

A qualidade do atendimento não é apenas expresso como um desejo e um realidade dos profissionais, mas também dos acompanhantes, que declaram ser bem atendidos nesta enfermaria de pediatria, principalmente quando comparam com outros serviços de saúde conhecidos: $O$ atendimento... ele [a criança] é bem tratado no hospital (...), faz todos os exames que precisa serfeito, precisa internar, ele fica internado, os médicos sempre tá .... certinho ali em cima, as enfermeiras também .

Quanto à comunicação em si, os profissionais de saúde da unidade de pediatria estudada dizem ter um bom relacionamento com os acompanhantes das crianças internadas: $O$ meu relacionamento com a mãe do Reginaldo eu acredito ser muito bom, é ela quem sempre me procura quando precisa de algo, a gente tem assim até uma cumplicidade, uma brincadei$r a$, vez ou outra a gente tá brincando.

Por outro lado, os funcionários, em geral auxiliares de enfermagem - que estão numa posição hierárquica inferior na equipe de saúde, sem a mesma qualificação profissional dos médicos, enfermeiros, pedagogos ou psicólogos e, assim, mais próximos dos pacientes, pela condição social semelhante à dos usuários dos serviços públicos - relatam que esses mesmos acompanhantes são a fonte de diversos conflitos na enfermaria, quando, por exemplo, eles 
tentam interferir no trabalho da equipe, opinando nos cuidados com a criança realizados pelos profissionais. Como relatou uma auxiliar de enfermagem: ela [a mãe] não quer nem que você chegue perto da criança. Como que você vai cuidar? E demora pra ela aceitar. Não é fácil. Outras mães elas.. a criança tá aqui, ela põe uma cadeira ali, estica a perna.. pra você chegar, você entrar, sair, é difícil. Às vezes, não é como a gente deveria fazer, tem que ser como ela quer e isso atrapalha. Isso que atrapalha: é como ela quer! Tem mãe que quer do jeito dela! Quando já tá há muitos meses aqui reclama... a gente não leva em consideração o que elas falam, a gente ouve e passa para frente, fica quieta, como eu, eu ouço falar e falar e fico quieta, se reclamar alguma coisa, fico quieta. Às vezes, elas falam assim, não é aquilo que elas falam... É assim: a mãe que fica aqui, eu acho, fica três meses, já está acostumada a ver uma medicação, daí, ela reclama, mas cada funcionário tem um jeito de colocar a medicação.

Os conflitos tendem a aumentar quanto maior o tempo de internação, uma vez que os acompanhantes mudam o seu comportamento na enfermaria, interferem mais no trabalho da equipe, passando a fazer parte da dinâmica do local. Reclamam com mais freqüência, desgastados pelo tempo de hospitalização do filho, diante dos problemas que esta situação acarreta na vida pessoal e familiar.

Frente aos conflitos mencionados, os próprios profissionais e funcionários tentam buscar explicações que justifiquem os desentendimentos com os acompanhantes, tais como a situação de hospitalização que traz angústia e ansiedade ${ }^{1,9,21}$, a patologia da criança, ou sua evolução durante a internação: Até acho que tem tudo isso, é uma série de coisas. Acho que a angústia da mãe, de tá vendo o filho doente, que não é fácil, internado, já não é fácil ver doente, imagina doente e internado; então, acho que isso angustia, no sentido de estar num lugar que não é a casa dela, de repente está desconfortável, não dorme bem, tem outras crianças no quarto, choram, sei lá, é a luz que ascende, a enfermeira que entra, etc., né? É... as vezes a própria patologia da criança, é uma coisa complicada (médico).

Para além da particularidade da situação de hospitalização, os profissionais buscam também respostas para os conflitos nas próprias relações humanas, sobretudo no que se refere às divergências quanto aos valores das diversas pessoas que interagem na enfermaria de pediatria, como foi explicitado na fala de uma enfermeira: você lida com gente, é muito difícil. Então, às vezes, tem ....tem algum tipo de coisa nesse sentido. De algumas mães serem mais questionadoras, outras mães serem mais exigentes, outras mães serem mais, como é o caso das adolescentes, mais é... liberal ...querem fazer algumas coisas que nem sempre poderiam, então é difícil porque você está lidando com vários tipos de pessoas, com os pais, com os funcionários, que tem culturas, valores diferentes, é difícil, muitas vezes os valores se chocam, e você tem que dar uma de mediadora, tem que usar muito bom senso, tem que ver é ...é um funcionário não aceita que a mãe vá embora e você tem que explicar que isto não é uma prisão, então é esse tipo de coisa...

Os profissionais trabalham freqüentemente com imagens pré-concebidas do que sejam "boas mães", as que colaboram com a equipe, que cumprem as funções que lhes são designadas, em contraposição àquelas que geram conflitos na enfermaria e são difíceis de lidar, questionadoras. Diante dessas acompanhantes, consideradas difíceis, os profissionais procuram $n \tilde{a} o$ se envolver muito, numa postura de evitar o conflito, deixam-nas reclamar sem respostas, $\mathrm{o}$ que estabelece um contato menor, dificultando a aproximação. Percebemos que o cuidado exercido pelo profissional e sua disposição para co- 
municar-se e se relacionar dependem de como o paciente e seu acompanhante se comportam, enfim, do julgamento moral que deles faz o profissional. Neste sentido, Helman ${ }^{2}$ ressalta como o comportamento do paciente condiciona a reação do profissional: "as pessoas com dor obterão o máximo de atenção e solidariedade se seu comportamento corresponder à visão social de como devem fazê-lo" (p. 172).

Os profissionais dizem que "explicam tudo". Observamos, entretanto, que, apesar das intenções, nem sempre isto acontece, uma vez que a "explicação" quase sempre utiliza um código de linguagem de domínio do profissional, que não necessariamente considera a forma como esta foi recebida. Vivenciamos uma situação em que o médico afirmava: mas ele, pra mãe dele, tudo, eu me dava bem com eles sempre expliquei tudo... pros pais dele, pra quem viesse aí me perguntar essas coisas; e eu acho que eu sempre fui claro com ela ... Fui claro, ela vinha perguntar as coisa pra mim, sem problemas. Eu acho que ela... não sei se ela tem alguma queixa de mim. Eu sempre procurei deixar bem claro o que tava acontecendo. No entanto, essa mãe durante o período em que foi visitada pelo pesquisador para a interação com o seu filho, várias vezes se mostrou angustiada por não saber o que ia acontecer com o seu filho, uma vez que um dos médicos dizia uma data para a alta hospitalar e outro lhe dizia para esquecer da alta que ia demorar. Esta mãe não foi esclarecida sobre o porquê da demora do resultado dos exames, dos quais dependia a previsão de alta, apesar de manifestar-se a esse respeito.

Em relação à comunicação dos profissionais com o paciente pediátrico, a maioria dos profissionais respondeu positivamente à pergunta: "como você vê sua relação com as crianças internadas? Disseram, de modo geral, ter um bom relacionamento: sei lá, uns $70 \%$ eu me dou muito bem e consigo até às vezes tirar ela do mau humor que ela tá.. por tá aqui, né? Ninguém gosta de tá no hospital. Aí as outras, às vezes tá meio ruim, é meio muito.. é... sabe....chorona, não é chorona a palavra, é manhosa, com muita manha daí, aí fica mais difícil assim, agora... abriu uma brechinha pra mim, eu acabo me dando muito bem com ela.

Foi ressaltado pelos profissionais que a relação com as crianças era modificada pela presença dos pais, reafirmando que uma boa relação com os pais era fundamental para uma boa relação com as crianças: (...) e a criança também, ela muda bastante quando os pais estão juntos. Quando tá sozinha é uma coisa, quando tá junto é outra. Mas se eles também vêem que a gente se relaciona bem com os pais, isso melhora.

As relações que a equipe médica e a de enfermagem estabeleceram com as duas crianças selecionadas para este estudo se mostraram bastante diferentes, em cada caso, de acordo com o relato dos profissionais. Com relação ao Denis, os profissionais ressaltaram o fato de ele ser maior que as outras crianças, além das características de sua personalidade, como fatores que dificultavam a relação: $o$ Denis já era maior, então, eu não brincava tanto com ele como eu brincava com os de seis anos, cinco anos.

O mesmo fator, a idade avançada, adquire outra conotação no caso de Reginaldo. Sua idade era vista pelo médico que o acompanhava como um fator positivo, facilitador da relação: Ele já tem catorze anos, então, é um relacionamento diferente. Com uma criança pequena você depende mais da mãe pra te dar as informações, no caso dele, eu conversava diretamente com ele, não tinha intermediários (...) E, acho que meu relacionamento com ele foi muito bom, muito positivo assim, foi muito legal.

Os depoimentos dos profissionais, sobretudo médicos pediatras, mostram o quanto a percepção da possibilidade de comunicação 
entre profissional e paciente está condicionada à linguagem oral, limitando a disposição do profissional frente a crianças menores, com quem apenas "se brinca", dados seus limites quanto às formas de expressão verbal próprias do mundo adulto. Desconsidera-se o potencial de comunicação que a brincadeira encerra $^{22}$, por configurar a forma de expressão infantil, por excelência, por meio da qual a criança manifesta sua própria percepção da doença e da dor que sente.

Observamos, entretanto, que o diálogo dos médicos, mesmo no caso do Denis - com quem conversava diretamente, sem intermediários - foi bastante limitado, focalizado na busca de fatores desencadeantes da doença e dos sinais perceptíveis da doença, segundo o conhecimento biomédico que informa as prática de saúde. A busca dos sintomas, expressos pelo paciente, resumiam-se a conversas a respeito da doença realizadas frequientemente apenas com a mãe.

A maior proximidade dos profissionais com o Reginaldo pode ser atribuída ao tempo de internação, mais prolongado que o de Denis; não era sua primeira internação no hospital e ele necessitava ir ao hospital regularmente, devido às características de sua doença. Grande parte dos profissionais entrevistados, em relação ao Reginaldo, já tinha uma familiaridade com ele.

\section{CONSIDERAÇÕES FINAIS}

Tendo em mente que o objetivo do nosso estudo foi o de analisar como ocorre a comunicação entre a criança, o acompanhante e o profissional da saúde na enfermaria pediátrica de um hospital escola; e avaliar se a indagação inicial que motivou esta pesquisa é considerada um problema para os protagonistas da situação estudada, podemos fazer algumas considerações.
Percebemos que a comunicação é valorizada, em princípio, pelos protagonistas da enfermaria. Os profissionais da saúde demonstram uma real preocupação com o cuidado da criança, bem como os acompanhantes, que procuram questionar o que está ocorrendo com sua criança. No entanto, pode-se dizer que nossos pressupostos não são de fato, vividos como problema, quer pelos profissionais, quer pelos acompanhantes, na medida em que falhas na comunicação existente entre eles não são reconhecidas nas suas falas, e, quando porventura o são, não são consideradas como um problema da assistência à saúde, nem vistas como empecilhos para sua eficácia. Quando os profissionais diziam que informavam o acompanhante, revelava-se uma ação unilateral, uma vez que nem sempre se preocupavam como a forma como era entendida a informação. O suposto informado permanecia sem entender o que estava acontecendo, o que gerava angústia e desentendimentos nas relações.

Observamos que embora a criança seja o ator principal neste cenário, ou seja, é ela que está doente e necessita estar internada, esta não é percebida como sujeito da ação, a ser incluído na relação estabelecida pela equipe com a pessoa responsável pela criança. Os profissionais estão lá para cuidar da criança; entretanto, para efetivar seu trabalho, necessitam da intermediação de outro adulto, afetivamente relacionado à criança, que quase sempre é a mãe, alegando-se que é nesta que a criança confia.

A prática pediátrica assenta-se, assim, sobre os elos de confiança entre a mãe e a criança, quando esses existem. Tomando esses elos como pressupostos e contando com eles para a eficácia de seu tratamento, o profissional tende a não buscar estabelecer diretamente com a criança uma relação de confiança, tendência reforçada pelo comportamento da mãe, que muitas vezes dificulta ou impede essa relação. Essa atitude implica que a comunicação entre profissional e paciente pediátrico depende da 
relação da criança com a mãe/acompanhante, evidenciando os limites da relação de assistência à saúde, sobretudo quando não houver entre a criança e seus familiares um vínculo saudável, que poderia ser trabalhado pelo profissional no atendimento.

Concluímos, então, que a comunicação se estabelece preferencialmente entre o profissional e o acompanhante, em função da criança, mas nem sempre com a participação desta. Seja na intenção do acompanhante manter a criança "protegida" da situação vivida, ou por uma dificuldade do próprio profissional em perceber a criança como um ser individualizado, um sujeito em desenvolvimento, mas com existência própria, o personagem central de nossa discussão era, muitas vezes, deixado à parte na construção das relações. Os profissionais de saúde que atuam em pediatria ao buscar o elo de confiança com a mãe/acompanhante para aproximar-se da criança, tendem a relegar a criança a plano secundário, privilegiando a relação com a mãe.

Vemos, assim, que a forma de comunicação dos profissionais com a criança e seus acompanhantes se reflete diretamente na qualidade de vida da criança dentro do hospital, uma vez que a criança, em vez de uma relação direta com o profissional, fica na dependência da relação deste com o acompanhante, comprometendo o que poderia ser um vínculo enriquecedor para ambos, profissional e paciente pediátrico.

\begin{abstract}
The research deals with difficulties in the communication between health professionals and pediatrics patients, under hospitalization conditions. Considering that an effective communication involves mutual recognition, the research focused both patients and professionals, in order to understand the communication between each other and the ways they interact. Given the problem stated, the methodology is qualitative and the method, the case study. The field research was developed in a public university hospital in the city of São Paulo. A comunicação entre os profissionais de pediatria e a criança hospitalizadaTwo children were chosen for study according to the following criteria: in school age and staying in the hospital over one week. A systematic tracking of these two children was made, through observation and the family members and professionals involved in the children's care and treatment were interviewed, covering most of the children interpersonal relations in the hospital. We observed that the communication was established preferably between professionals and the children's family members, but not necessarily with the children's participation, living then on a secondary level in the relationship.
\end{abstract}

Key words: Communication. Hospitalized child. Professional-pacient relationship. Child care. Pediatrics.

\section{REFERENCIAS}

1. Bordin IAS, Corrêa MCMR. Ansiedade da crian ça hospitalizada: ausência ou dificuldade na rela ção equipe-paciente? Revista Paulista de Pedia tria 1990; 29:67-70.

2. Helman CG. $2^{\text {a }}$ ed. Cultura, saúde e doença. Porto Alegre: Artes Médicas; 1994.

3. Tosta RM. A atividade lúdica da criança no con texto da internação hospitalar. Boletim Clínico da Faculdade de Psicologia da PUC-SP; 1997.

4. Sadala MLA, Antônio ALO. Interagindo com a criança hospitalizada: utilização de técnicas de medidas terapêuticas. Revista Latino Americana de Enfermagem 1995; 3(2): 93-106.

5. Viegas D. Relação pediatra-paciente. Revista Si nopse de Pediatria, 2000; 3.

6. Hofling CK et al. Enfermaria psiquiátrica. $2^{\mathrm{a}}$ ed. México: Interamericana; 1970.

7. Winnicott DW. A criança e o seu mundo. $3^{\mathrm{a}}$ ed. Rio de Janeiro: Zahar; 1975.

8. Ruesch J. Comunicación terapeutica. Buenos Ai res: Paidós; 1964.

9. Mouth RG., Silva SLA. Repercussões psicológi cas da hospitalização na criança e sua família. Pediatria Moderna 1984;19(8):387-91.

10. Becker H. Métodos de pesquisa em Ciências So ciais. São Paulo: Hucitec; 1994. 
11. Da Matta R. O ofício do etnólogo, ou como ter "anthropological blues". In: Nunes E, organiza dor. A aventura sociológica: objetividade, paixão, improviso e método de pesquisa social. Rio de Janeiro: Zahar; 1978. p. 23-35.

12. Foot-Whyte W. Treinando a observação partici pante. In: Guimarães AZ, organizadora. Desven dando máscaras sociais. $2^{\mathrm{a}}$ ed. Rio de Janeiro: Francisco Alves; 1980. p.77-86.

13. Sarti CA. Porque usar técnicas etnográficas no mapeamento. In: Lescher AD, Sarti CA, Bedoian G, Adorno RCF, Silva SL. Cartografia de uma rede. reflexões sobre um mapeamento da circulação de crianças e adolescentes em situação de rua da cidade de São Paulo. São Paulo/Brasília: Projeto Quixote-UNIFESP/FSP-USP/Fundo das Nações Unidas para o Controle Internacional de DrogasUNDCP/Ministério da Sapude-Governo Federal; 1998. p.3-7.

14. Velho G. Observando o familiar. In: Nunes EO, organizador. A aventura sociológica: objetivida de, paixão, improviso e método de pesquisa soci al. Rio de Janeiro: Zahar; 1978. p. 37-46.

15. Piaget J. A equilibração das estruturas cogniti vas. Rio de Janeiro: Zahar; 1976.

16. Rappaport CR, Fiori WR, Davis C. Teorias do de senvolvimento: conceitos fundamentais. Vol. 1. São Paulo: EPU; 1981.

17. Pereira SR. (Re)Construindo o hospital: a ótica da criança portadora de doença renal crônica. [tese]. São Paulo (SP): Programa de Pós Gradua ção em Enfermagem da UNIFESP; 1999.

18. Víctora CG, Knauth DR, Hassen MNA. Pesquisa qualitativa em saúde. Porto Alegre: Tomo Editori al; 2000.

19. Santos MER. (organizadora) O impacto emocio nal da hospitalização da criança. J. Ped 1984; 56(5):341-44.

20. Santos MER. A hospitalização da criança: a visão do familiar. J. Ped 1984; 56(6):391-94.

21. Trezza EMC, Trezza E. Prejuízos emocionais à cri ança hospitalizada. Pediatria 1985;7:181-83.

22. Huizinga J. Homo ludens. $4^{\text {a }}$ ed. bras. São Paulo: Perspectiva; 1996 [1938]. 